\title{
Preschool Students' Understanding of a Geometric Shape, the
} Square

\author{
La Comprensión Conceptual De Los Niños De Preescolar En Las Formas \\ Geométricas, El Cuadrado
}

\author{
Erdoğan Halat ${ }^{*}$ \\ Ümmühan Yeşil Dağl1 ${ }^{* *}$
}

\begin{abstract}
The purpose of this study was to explore preschool children's conceptual understanding of geometric shapes, the square in particular. There were a total of 115 children, 61 girls and 54 boys, from state preschool education programs, who participated in the study. The data were collected in two semesters through interviews in a oneon-one setting, where the researchers administered a paper-pencil test to the participants. The test included six questions. One question asked children to draw a square, one question asked to select the square among three other geometric shapes, three questions asked to differentiate the square among five to seven geometric shapes which were printed in rotated directions and in various fonts and sizes and one question asked to identify a picture of a square-like real life object among a selection of pictures. The findings showed that $65 \%$ of children were able to draw a square accurately, and $77 \%$ of children were able to identify a picture of a square-like object. Approximately $69 \%$ were able to differentiate three squares in different sizes among five geometric shapes, while $27 \%$ of the remaining were not able to identify the square in smaller sizes. Approximately $79 \%$ in one task and 56\% in another task were unsuccessful in identifying squares in rotated directions. Moreover, there was no gender difference in the test between boys and girls. Findings were interpreted linking to Duval's theory, van Hiele's theory, Prototype theory and Simon's task design model.
\end{abstract}

Keywords: Preschool children. Square. Geometric shapes. Gender.

\section{Resumen}

El propósito de este estudio fue explorar la comprensión conceptual de los niños de preescolar en las formas geométricas, el cuadrado en particular. Hubo un total de 115 niños, 61 y 54 niñas, de programas de educación preescolar del estado, que participaron en el estudio. Los datos se recolectaron en dos semestres a través de entrevistas en un uno-a-uno, donde los investigadores administraron una prueba papel y lápiz a los participantes. La prueba incluía seis preguntas. Una pregunta de los niños, era que dibujaran un cuadrado, otra pregunta les pedía que seleccionaran el cuadrado entre otras tres formas geométricas, la tercera pregunta les pedía distinguir el cuadrado de entre cinco a siete formas geométricas que fueron impresas en direcciones rotadas y en diversas fuentes y tamaños, y la última pregunta les pedía identificar una imagen de un objeto cuadrado-como un objeto real de entre una selección de fotos. Los resultados demostraron que el $65 \%$ de los niños fueron capaces de dibujar un cuadrado con precisión, y un $77 \%$ de los niños fueron capaces de identificar una imagen de un objeto cuadrado. Aproximadamente el 69\% eran capaces de diferenciar tres cuadrados de diferentes tamaños entre cinco figuras geométricas, mientras que $27 \%$ de las restantes no fueron capaces de identificar el cuadrado en tamaños más pequeños. Aproximadamente $79 \%$ en una tarea y el $56 \%$ en otra tarea fracasaron en la identificación de cuadrados en las direcciones rotadas. Por otra parte, no hubo diferencias de género en la prueba

\footnotetext{
* Assoc. Prof. Dr., Faculty of Education, Afyon Kocatepe University, ANS Campus, Afyonkarahisar, Turkey. Email: ehalat@aku.edu.tr

** Assoc. Prof. Dr., Faculty of Education, Yildiz Technical University, Davutpasa Campus, Esenler, Istanbul, Turkey. E-mail: uydagli@yildiz.edu.tr
} 
entre niños y niñas. Los resultados se interpretaron siguiendo la teoría de Duval, la teoría de van Hiele, la teoría de prototipo y el modelo de diseño de la teoría de Simon.

Palabras clave: Los niños preescolares. Cuadrado. Formas geométricas. Género.

\section{Introduction}

Research findings suggest that forming a conceptual understanding of geometric shapes begins in early years of life and that children's understanding becomes pretty stable at the age of 6 (GAGATSIS \& PATRONIS, 1990). However, not until recently has geometry received significant attention (OBERDORF \& TAYLOR-COX, 1999; CLEMENTS, 2004; CASEY et al., 2008). In their joint position statement, the National Council of Teachers of Mathematics (NCTM) and the National Association for the Education of Young Children (NAEYC, 2002) identify five mathematics content areas for teachers to introduce: numbers and operations, geometry and spatial sense, measurement, patterns/algebraic thinking, and displaying and analyzing data. As articulated in content standards, geometry has been identified by NCTM (2000) as one of three major areas (the other two being number and measurement) that are particularly important for 3- to 6-year-olds. Some expectations set by NCTM (2000) for children in preschool through second grade regarding geometric shapes are

\footnotetext{
...recognize, name, build, draw, compare, and sort two- and three-dimensional shapes;... describe attributes and parts of two- and three-dimensional shapes; ...investigate and predict the results of putting together and taking apart two- and three-dimensional shapes; ... recognize and apply slides, flips, and turns; $\ldots$ recognize and create shapes that have symmetry; ...create mental images of geometric shapes using spatial memory and spatial visualization; ...recognize and represent shapes from different perspectives; ...recognize geometric shapes and structures in the environment and specify their location (www.nctm.org).
}

Similar mathematics expectations are also set in the Turkish preschool education program. It includes mathematics expectations in numbers and operations, patterns, measurement, geometry and spatial sense. Focusing on the expectations for geometric shapes, specifically, three goals were set: (1) name the geometric shapes, (2) describe the attributes of the geometric shapes, and (3) recognize the objects that are similar to geometric shapes (National Ministry of Education [Milli Egitim Bakanligi; MEB], 2013). Although state funded preschool programs require teachers to rate children whether they have reached the goals or not by the end of the semester, the ratings are limited with evaluating children's skills in naming geometric skills; being far from evaluating skills in specific geometric shapes, such as square or triangle, or identifying the areas in which they have difficulty. With this research, 
we examined children in Turkish preschool programs in terms of their geometrical understanding of the square and whether and in what contexts they experience difficulties in recognizing and differentiating the square.

\subsection{Theoretical models of geometric understanding}

Several theoretical models have guided research studies in describing and understanding development of geometrical understanding and reasoning (JONES, 1998). Among them, a French psychologist Raymond Duval, approaching from a cognitive and perceptual perspective, suggests that geometrical reasoning involves three cognitive processes: the visualisation process, the construction process and reasoning. The visualisation process is the identification of a space representation (e.g., a 2- or 3-dimensional figure) based on particular laws. The construction process includes using tools such as a ruler or geometrical software to construct shapes. The reasoning process involves providing explanations, or descriptions through natural speech or formal definitions. The visualisation, construction and reasoning processes are all dependent to and independent from each other. That is, the three cognitive processes can be performed separately such that visualization does not depend on the construction or reasoning, or vice versa; however, the interaction among them is crucial for proficiency in geometry (DUVAL, 1998).

Duval (1995) also asserts a cognitive model in the analysis of geometric figures. He calls this model "cognitive apprehension" there are perceptual, sequential, discursive and operative apprehensions. Perceptual apprehension is when one perceives or recognizes at first glance looking at a geometric shape. Sequential apprehension is needed when a construction process is involved. Discursive apprehension is about mathematical properties one gets through speech or derives from the given properties. Operative apprehension refers to modifying the figure, or obtaining other configurations of a figure using a starting figure, such as moving, or rotating the figure. A geometric figure requires functioning in discursive and visual registers, and solving geometrical problems requires interaction among these apprehensions (DUVAL, 2006).

Another theory was developed by Dutch mathematician Van Hiele (1986). He proposed that students go through five developmental stages of geometrical understanding. In the first stage, Stage 0, called visualization, children identify, recognize, and name geometric figures based on their familiar appearance, usually on prototypes, by attending to the whole figure, not to its right angles, number of corners, and sides or equal side lengths. A prototyped 
square is usually the one with the bottom and upper sides printed parallel to the bottom of the page. Hence, a square that does not match the prototyped one (e.g., squares that are in different sizes, or rotations), is not considered as a square by children at this stage. In the second stage, Stage 1, analysis, children begin to recognize the attributes of the shape. Thus, when they encounter a figure, they analyze the numbers of sides, corners, and lengths of the sides of the figure and decide whether it is a square or not. For example, a child at the visualization stage identifies the square on the left in Figure 1, as a square as it is a prototyped one, but may not identify the square on the right because it is slightly rotated. On the other hand, a child at the analysis stage recognizes that the shape on the right side is also a square as it has four sides with equal lengths and four corners (Readers interested in more about the stages of van Hiele may want to see the research studies (i.e., VAN HIELE, 1986; FUYS et al., 1988; HALAT, 2008).

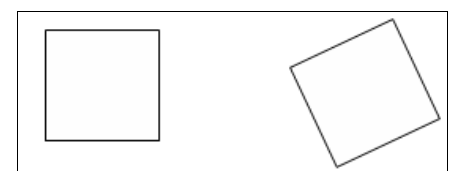

Figure 1- Two perspectives of a square. Adapted from "In-Service Middle and High School Mathematics Teachers: Geometric Reasoning Stages and Gender," by E. Halat, 2008, The Mathematics Educator, 18, p.8. Copyright 2008 by Mathematics Education Student Association. Adapted with permission.

Studies inspired by this theory have found that children at the preschool age are usually in the first or second stages (e.g., BURGER \& SHAUGHNESSY, 1986; CLEMENTS et al., 1999; HALAT, 2006 \& 2007). At the same time, disagreeing with van Hiele's position that children can act at only one stage at a time, and the stages are not discrete, Clements and his colleagues (CLEMENTS \& BATTISTA, 1992: CLEMENTS et al., 1999) suggest that "children making the transition to the next level sometimes experienced conflict between the two parts of the combination (prototype matching vs. component and property analysis), leading to incorrect and inconsistent task performance" (CLEMENTS et al., 1999, p. 206). They also argue that there is a precognition level before Van Hiele's visual stage, called the syncretic level, where children use declarative knowledge.

Research emphasizes the role of the prototype for children in identifying and recognizing geometric shapes (MASON, 1989; CLEMENTS, 1999; OBERDORF \& TAYLOR-COX, 1999; GAL \& LINCHEVSKI, 2010). Indeed, Prototype Theory (ROSCH, 1973) gives a framework to explain how and why children use the prototype of a geometric shape in identifying and classifying a figure into particular geometric shape category. According to the Prototype theory, individuals form concepts based not primarily on the formal rules or definitions. They form the concepts based on prototypes, which is the typical 
and most frequently represented example(s) of the concepts. The prototypes are the central member of a concept and any other figure is categorized into the concept based on the similarity to the central member or family resemblance. For example, for triangle concept, a central member is an equilateral triangle with a horizontal base; any other types of triangles have a family resemblance. Research findings provide evidence about the influence of the prototype on identification of a shape. In studies with 3-6 year-olds, a significant proportion of children failed to categorize non-prototypical triangles into the triangle category (HANNIBAL \& CLEMENTS, 2000; YESIL-DAGLI \& HALAT, 2016) and rectangles into the rectangle category (CLEMENTS \& BATTISTA, 1992). In another study with upper grades (fifth through eighth graders), children had difficulty in identifying a non-prototyped triangle, which was a twisted equilateral triangle with a base that was not parallel to the bottom of the page (HERSHKOWITZ, 1989).

\subsection{Purpose of the study}

The purpose of this study was to explore preschool children's conceptual understanding of one geometric shape, the square. In particular, the researchers aimed to identify whether and in what contexts children experience difficulties in recognizing and differentiating the square. Previous studies (e.g., HERSHKOWITZ, 1987, 1989; RAZEL \& EYLON, 1991; CLEMENTS \& BATTISTA, 1992; CLEMENTS et al., 1999; HANNIBAL \& CLEMENTS, 2000) have usually involved several geometric shapes simultaneously in a study, which limited our understanding if and in what situations children experience difficulties for a specific geometric figure. One geometric shape, the square, was selected for the study, with the assumption that visual representations of and frequency of exposure to each geometric shape vary, so do, as previous research has shown (BURGER \& SHAUGHNESSY, 1986; MAYBERRY, 1983), children's difficulties forming conceptual understanding for each geometric shapes. The geometric shape, square, was selected because among the limited studies, only a few included squares (RAZEL \& EYLON, 1991; CLEMENTS et al., 1999), leaving a gap in the literature.

\section{Method}

\subsection{Participants}


The study involved 115 preschool children, 61 girls and 54 boys, recruited from three state-funded preschool education programs located in neighborhoods representing different socioeconomic status. The children were grouped as 5-year-olds and 6-year-olds by their program when they were enrolled. The ages of the children in months were not available to the researchers. The researchers practiced convenience sampling procedure in the selection of the schools and students. According to McMillan (2000), this sampling technique is commonly used in educational studies.

\subsection{Data collection procedure and materials}

This study took place in a state university located in the western part of Turkey. The data were collected during the spring semester of 2014 and fall semester of 2015 through interviews in a one-on-one setting, where the researchers administered a paper-pencil test to the participants. The researchers developed a test including six tasks. Simon and colleagues' (2004) work about designing mathematics learning activities/tasks were used when designing the tasks. Simon and colleagues (2004), inspired by Piaget's idea on reflective abstraction, elaborate a mechanism, which they called the reflection on activity-effect relationship, for mathematics conceptual learning. In that mechanism,

Activity refers to mental activity that provides the raw material for the construction
of a new conception"...."activity sequence refers to a set of actions used in an
attempt to meet a goal". This goal is set by the learner and is "not necessarily
conscious"... "Effects are not the output of a 'black-box' experience. Rather, they are
structured by assimilatory conceptions that the learner brings to the situation
(SIMON et al., 2004, p.320-321).

They argue that this mechanism offers a guideline in planning and use of mathematical tasks in a lesson to promote mathematical conceptual understanding and suggest four steps: The first step is specifying what students know (current state of knowledge), the second step is specifying what students should know (pedagogical goal state, set by the learner), the third step is identifying the sequence of activities to take the students from current state to the goal state, and the final step is selecting the task.

In his earlier work, Simon (1995, p. 35) uses the term hypothetical learning trajectory to describe "the teacher's prediction as to the path by which learning might proceed". This path includes "the learning goal which defines the direction, the learning activities, and the hypothetical learning process - a prediction of how the students' thinking/understanding will evolve in the context of the learning". Learning activities a piece of the hypothetical learning theory is articulated in steps two to four through the reflection on activity-effect relationship 
mechanism such that students set a goal (to accomplish a task given by the teacher/researcher), initiate a sequence of actions to meet the goal, noticing the effects and may be reiterating the actions, and finally reflecting on the experiences (Simon et al., 2004). Simon (1995) argues that tasks or problems planned for learners should not be limited to situations that are appropriate to problem context, or familiar to the learner. Rather, problem contexts that force learners to carry ideas or knowledge beyond the narrow context to novel or unfamiliar situations should be created to challenge the learner's conception. Providing such challenges lead conceptual growth. He suggested observing students' solving mathematics problems and conceptual difficulties in a challenging and rich set of situations.

Accordingly, the first task designed in this research required the participants to draw a square, through which children were motivated to represent a mental image of the geometric shape, without providing an example or a reminder. This task was given in the first place intentionally to identify if they had already formed an image of the square and could have represented it before completing the subsequent tasks which include square figures in various forms. The last task was identifying square-like real-life objects. Remaining tasks were designed to identify the geometric shape square within different contexts. The tasks were presented to children in an order from simple to complex. This was done with an expectation that it would help children complete all tasks without being overwhelmed by complex tasks, being discouraged to respond, or feeling unsuccessful if they found the tasks to be too hard. The second task asked the participants to select the square among three geometric shapes; a square, a star and a triangle. All geometric shapes were prototyped examples of the shapes they represented and in standard sizes. The third task measured whether children were able to recognize the squares in different sizes and contained figures of three squares in three different sizes among two others (a star and a circle), for a total of five geometric shapes. All figures were printed on a line. We added a figure of a rotated square in the fourth and fifth tasks. In the fourth task, there were five geometric shapes, one of which was a circle and the other one was a hexagon, partially looking similar to the rotated square. All figures were printed on the same line. In the fifth task, we removed the hexagon and included a prototyped triangle and a star, thus there were six geometric shapes. In addition, the figures of geometric shapes were not lined up, rather were placed randomly at upper or lower positions relative to each other.

During the interviews, the researchers read the questions to the preschoolers and they put their fingers on each figure which they thought was a square. When the children were 
working on the test, the researchers ensured that children were comfortable and took as much time they needed to think and respond. Interview times ranged between 6 to 15 minutes.

\subsection{Data analysis}

The researchers scored the participants' responses for correctness. Frequency analyses of responses were used to determine in which areas the participants had difficulty. In the first, second and last tasks, scores were determined by whether the child could draw, identify a square, or a square-like real life objects, respectively, $(=1)$ or not $(=0)$. For the third, fourth, and fifth items, where the children were expected to identify the squares which were in different sizes and rotated in different directions, their correct responses were counted for each combination of answers (e.g. number of children who identified all three squares, or number of children who identified the small and medium size square etc).

\section{Results}

\subsection{Drawing a square}

The first task included asking children to draw a square. The drawn figure was accepted as a square if the drawing had four corners with approximately 90-degree angles, four sides with (approximately) equal lengths and the sides were (approximately) parallel to each other. Figures 2 and 3 display samples of incorrect and correct drawings of squares by children, respectively. The scores showed that approximately $65 \%(n=75)$ of the children correctly drew a square. About 4\% $(n=4)$ did not draw anything, and $31.3 \%(n=36)$ drew a four sided geometric figure or a geometric figure, that could not be defined as a square.
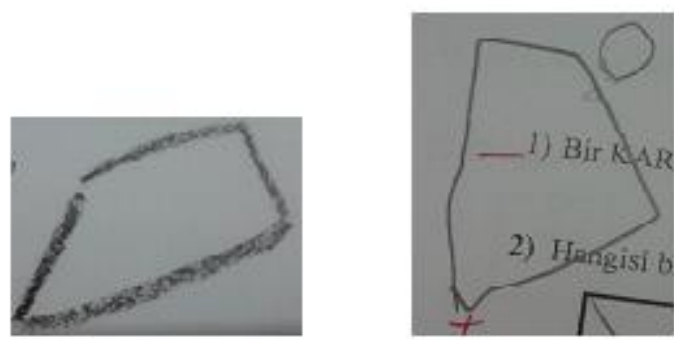

Figure 2 - Samples of incorrect drawings of square by children. 


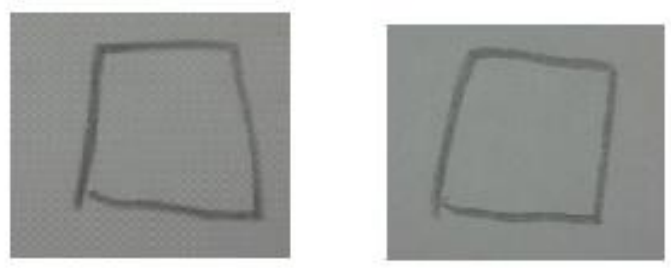

Figure 3 - Samples of correct drawings of square by children.

\subsection{Identification of a square among two other geometric shapes (a triangle and a star)}

This task required children to recognize the square figure among three geometric shapes (a square, a triangle, and a star) all of which were printed in the same size, and were typical examples of the shapes they represent. That is, the square was printed parallel to the bottom of the page, and the triangle was equilateral with a horizontal base (see Figure 4). The frequency analyses showed that all children were able to identify the square.
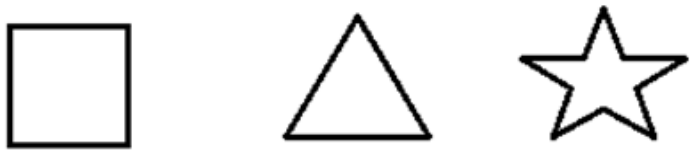

Figure 4 - Task 2

\subsection{Identification of the three squares in three different sizes among five geometric shapes}

In the task where there were figures of three squares in different sizes (small, medium, and large), and a circle and a star in regular sizes (see Figure 5), children demonstrated good success rates. That is, none of the children chose a circle or a star as a square. As shown in Table 1, approximately $69 \%(n=79)$ were able to identify all three squares in different sizes. Twenty two children $(19.1 \%)$ identified only the large square and nine children $(7.8 \%)$ identified both the large and the medium size square as a square. In other words, approximately $27 \%$ did not perceive the small square as a square.

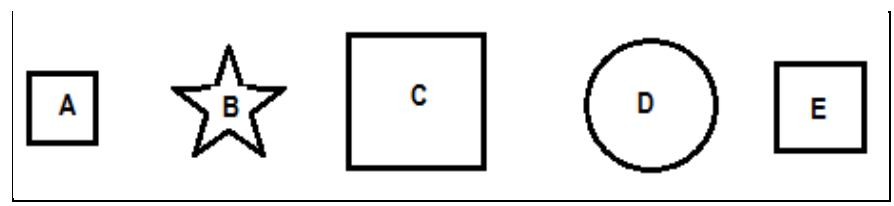

Figure 5 - Task 3 
Table 1 - Frequencies and percentages for identifications of squares in Task 3

\begin{tabular}{lcc}
\hline & $\mathrm{N}$ & $\%$ \\
\hline Selected all A (small), C (large), \& E (medium) & 79 & 68.7 \\
Selected only C (large) & 22 & 19.1 \\
Selected C (large) \& E (medium) & 9 & 7.8 \\
\hline
\end{tabular}

\subsection{Identification of a rotated square and two squares in two different sizes among five geometric shapes}

In the task where children were shown three pictures of squares, two of which were printed parallel to the bottom of the page, one in a regular size and the other one in a relatively smaller size, and a square that was rotated 45 degrees. There were also hexagon and circle figures in regular sizes given in the task. Figure 6 shows the task.

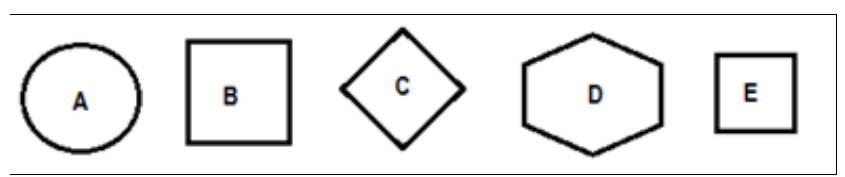

Figure 6 - Task 4

As shown in Table 2, almost $79 \%$ of children failed to identify the rotated square as a square. The percent of children who were able to recognize all three squares, two of which were in two different sizes and the third one was rotated, was $20.9 \%$. Approximately $57 \%$ of children identified two squares that were in different sizes and printed parallel to the bottom of the page, $11.3 \%$ identified the square that was larger in size and parallel to the bottom of the page and $3.4 \%$ identified the square that was relatively smaller in size and parallel to the bottom of the page. In addition, one child selected the hexagon, along with a square in larger size.

Table 2 - Frequencies and percentages for identifications of squares in Task 4

\begin{tabular}{lll}
\hline & $\mathrm{N}$ & $\%$ \\
\hline Selected all squares & 24 & 20.9 \\
Selected parallel and in regular size (B) \& parallel and in smaller size (E) & 66 & 57.39 \\
Selected parallel and in regular size (B) & 13 & 11.3 \\
Selected parallel and in smaller size (E) & 4 & 3.4 \\
Selected rotated (C) & - & - \\
\hline
\end{tabular}

\subsection{Identification of a rotated square and two squares in two different sizes among six shapes}

This task included the identification of three squares among six geometric shapes. As depicted in Figure 7, three of the geometric shapes were squares, two of which were printed 
parallel to the bottom of the page, one in a regular size and one in a relatively smaller size, and the other square was rotated 45 degrees and was in a regular size. The other geometric shapes were a circle, an equilateral triangle with the base parallel to bottom of the page, and a standard five point star, all being in regular sizes.

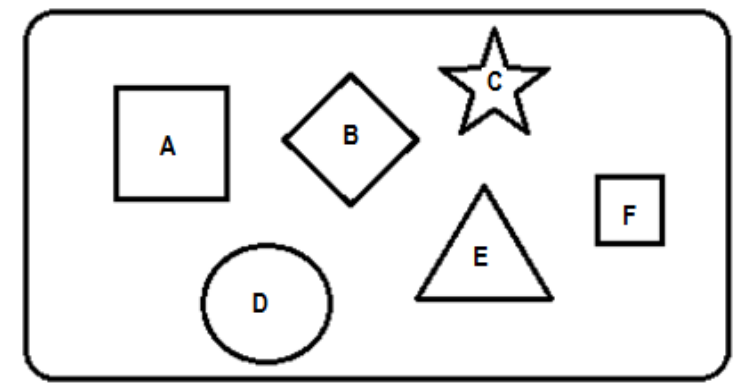

Figure 7- Task 5

As seen in Table 3, $44.3 \%$ of the children identified all three of the squares. It appeared that $56 \%$ of the children were not able to identify the rotated square. About $21 \%$ of the children were confused with the size and did not perceive a smaller sized square as a square.

Table 3 -Frequencies and percentages for identifications of squares in Task 5

$\begin{array}{lcc}\text { Selected all (Regular size (A) \& smaller size (F) and rotated (B) } & 51 & 44.3 \\ \text { Regular size (A) \& smaller size (F) } & 28 & 24.34 \\ \text { Regular size (A) } & 24 & 20.86 \\ \text { Rotated (B) } & 0 & - \\ \text { Left Blank } & 3 & 2.6\end{array}$

\subsection{Identification of a square-like real life object among three other real life objects}

In the sixth task, we included the pictures of four real-life objects, a frame, basketball, tent, and window, and asked children to identify a picture of a square-like object. Figure 8 depicts the picture of real-life objects.
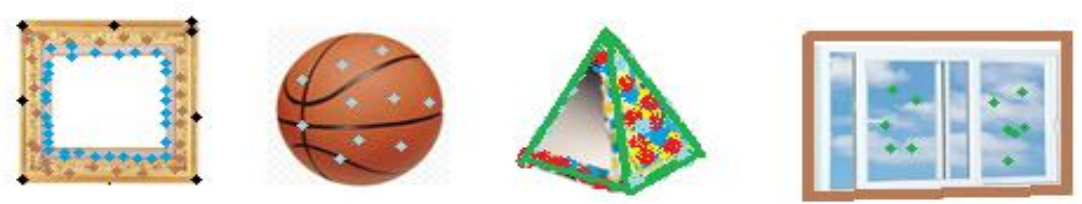

Figure 8 - Task 6 
Table 4- Frequencies and percentages for identifications of squares in task 6

\begin{tabular}{lcc}
\hline & $\mathrm{N}$ & $\%$ \\
\hline Empty & 7 & 6.1 \\
False & 20 & 17.4 \\
True & 88 & 76.5 \\
Total & 115 & 100 \\
\hline & Source: Research data
\end{tabular}

Source: Research data

Almost $77 \%$ of the participants gave the right answer for this question and chose the real life object that looks like a square (Table 4). But, roughly $17 \%$ of the participants chose the shapes of both frame and window as squares. It can be said that these preschoolers confused the square with the rectangle. It seems that the preschool children do not have many problems with selection of real life objects looking like a square.

\subsection{Gender related differences}

Table 5- Independent samples t-test results for gender

\begin{tabular}{llllll}
\hline Gender & $\mathrm{N}$ & Mean & SD & $\mathrm{T}$ & $\mathrm{p}$ \\
\hline Boys & 54 & 3.90 & 1.33 & 1.36 & 0.17 \\
Girls & 61 & 3.54 & 1.52 & & \\
Total & 115 & & & \\
\hline \multicolumn{5}{c}{ Source: Research data }
\end{tabular}

According to Table 5, the mean score of boys (3.90) on the test was numerically higher than that of girls (3.54). The mean score difference in terms of test scores was not statistically significant $[\mathrm{t}=1.36, \mathrm{p}=0.17>\alpha=0.05]$. In other words, there was no gender difference found with regard to achievement scores on the geometry test about squares in geometry between preschool boys and girls. Likewise, there were no gender differences detected in any question on the geometry test between preschool boys and girls.

\section{Discussion and conclusion}

This study investigated preschool children's conceptual understanding of one geometric shape, the square. In particular, their abilities to recognize the square in various sizes and in rotated form were examined. Five and six year-old children in three preschool programs participated in the study. Children completed six paper-pencil tasks, all printed on the same page, in various contexts where the numbers and types of geometric shapes, and 
whether all the shapes were printed on a line or in upper or lower positions relative to other shapes, and also sizes and rotation of the squares were varied.

The study findings indicated that most of the children were successful at drawing a square, differentiating the square from a circle and a star, and identifying a square-like real life object. These findings are lined up with the expectations of NCTM (2000) claiming that "In pre-K through grade 2 all students should recognize, name, build, draw, compare, and sort two- and three-dimensional shapes." However, a great majority of the children in the study were not successful in the identification of the rotated forms of the square in the tasks. This is in contrast with the expectation of NCTM (2000) stating that children should "... recognize and apply slides, flips and turns". In other words, agreeing with the literature (CLEMENTS et al., 1999), the findings from this study showed that children were predominantly successful in identifying a prototyped square, which was in regular size and printed parallel to the bottom of the page. On the other hand, based on the third and fifth task, approximately 19\%$11 \%$ of children did not identify the small size square. In addition, approximately $79 \%$ of children in task four and $56 \%$ of the children in task five were not able to identify the rotated square. These results may be linked back to the theories of geometrical understanding. From a cognitive and perceptual perspective of Duval (1995/1998), these results may imply that the children that participated in this study had functioning perceptual apprehension and were unable to function at operative apprehension yet. These findings may also suggest that, cognitively, children in the study identify the shapes through the visualization process, rather than reasoning process. From a perspective of Prototype theory (ROSCH, 1973), the majority of children in this study seemed to identify the square if it was a prototyped one, the central member of the square family, and to decide whether a rotated or smaller sized square was a square was based on how much it looked similar, family resemblance, to the central member of the square. Looking from Van Hiele's (1986) point of view, children in this study are in the visual stage, consistent with the results of several other research studies (e.g., BURGER \& SHAUGHNESSY, 1986; CLEMENTS et al., 1999; HALAT, 2006 \& 2007), as they appeared to identify the squares based on appearance, and not its properties or attributes.

On the other hand, this study also found that the success rate of preschool children in identifying non-prototyped squares varied across the tasks. That is, the success rate was higher when they were given tasks where the shapes were distinct and in smaller numbers. In addition, when the figures were given in a random order, not on the line, children showed more confusion in identifying a square in a smaller size (3\% in task 4 and $21 \%$ in task 5). In addition, they showed greater confusion in identification of the rotated forms of the square 
when they were provided with a similar shape (e.g., hexagon). That is, the percent of children who identified the rotated square in task 5 was higher than those in task 4 (44.3\% vs. $20.9 \%$, respectively), although task 4 had figures of five shapes printed on a straight line with a hexagon, which appears similar to a rotated square and task 5 included figures of six shapes given in random order without a hexagon. One possible explanation for the success rate variation in the identification of the non-prototyped square may be connected to the way the tasks were presented to the children. Performance differences of children across tasks may also indicate that designing learning tasks or problems in different contexts with various complexity and unfamiliarity, as suggested by Simon and colleagues (2004), facilitated children's capturing and understanding of a concept better. The other possible reason would be, as Clements and colleagues theorized, children who show inconsistent performance among the tasks may be transitioning to the next van Hiele level, and experiencing conflict between prototype matching and property analyses (CLEMENTS et al., 1999, p. 206).

The findings of this study shed some light on children's geometrical understanding and where they experience difficulty in identifying a shape; however, the results should not be generalized to all geometric shapes, as only the square was studied, or to children in different settings. Also, information about classroom teaching practices of geometric shapes would have been helpful in understanding and interpreting the results of the study. Future research should consider linking teaching practices and children's conceptual understanding of the geometric shape square and other figures.

Furthermore, research has documented that the effect of gender should be examined as a variable in analysis, even if it is not the major tenet of a research study (c.f., ARMSTRONG, 1981; ETHINGTON, 1992; GROSSMAN \& GROSSMAN, 1994; LEVINE et al., 1999; FORGASIZ, 2005; LLOYD et al., 2005; HALAT \& ŞAHIN, 2008). Over the past few decades, research shows gender- related differences with regard to achievement between boys and girls in many content areas of mathematics, including spatial visualization, problem solving, computation, and measurement (i.e., GROSSMAN \& GROSSMAN, 1994; LLOYD et al., 2005).

Although the main purpose of this current study was not about finding the differences between the accomplishment of boys and girls in mathematics, the researchers searched for the effects of gender on the achievement of preschool children and their perceptions of the square. There were no gender difference found in reference to drawing, selection, and rotated directions of a square on the test between boys and girls. In other words, gender was not a great factor for preschool children to identify the square. This finding of the study was lined 
up with the report of Clements et al. (1999) who stated that gender difference was assessed with analysis of variance for the square. There was no significant difference found between boys and girls on the overall scores of the square.

In short, the preschool children who participated in this study showed level-I (Visualization) geometry knowledge in squares and most of them were very successful in the recognition of a picture of square-like object. However, the participants who weren't successful were confused by the smaller square and the rotated square. In addition, the accomplishment level of the preschool boys and girls on the test was equal.

\subsection{Implications for practice}

The findings of this study suggest that preschool children's understanding of a square appeared to be limited to a prototype square, which is a square placed parallel to the bottom of the page and in a relatively larger size. Based on the findings, consistent with the previous research (MASON, 1989; OBERDORF \& TAYLOR-COX, 1999; YESIL-DAGLI \& HALAT, 2016), it can be speculated that preschool children are probably exposed to mostly prototypical examples of the shapes. In addition, it is highly likely that children do not have enough opportunities to discuss the critical attributes of the shapes due to limited exposure to the geometric shapes in various sizes and orientation. According to several studies (e.g., FUJITA \& JONES, 2006; FUJITA, 2012), conceptual understanding gained through the prototype figures may lead to misconceptions and wrong generalizations in learning. For instance, if a person learns about the parallelogram from the prototype shape of the parallelogram, s/he can have difficulties when calling a rectangle as a parallelogram. Thus, as suggested by other researchers (MASON, 1989; OBERDORF \& TAYLOR-COX, 1999; YESIL-DAGLI \& HALAT, 2016), the data gathered in this study implies that early childhood educators should provide children with opportunities to experience typical and atypical examples as well as non-examples of geometric shapes in various forms. In addition, as research (KLIBANOFF et al., 2006; RUDD et al., 2008) suggests, better classroom lessons about geometric shapes would improve preschool children's understanding of the square. Teachers should provide plenty of opportunities to discuss, compare and contrast the properties, characteristics and attributes of the shapes, thereby unfolding reasons for their thoughts and, in some cases, for misconceptions; yet they "should be careful and selective with the amount of math talk that they offer to young children" (BOONEN et al., p. 281). 
On the other hand, early childhood teachers may not have the knowledge about young children's mathematics learning (NAEYC/NCTM, 2002), particularly about their misconceptions and difficulties about geometric shapes. Early childhood teacher education programs should emphasize preschool children's misconceptions about geometric shapes in a mathematics method course. Preschool teachers should provide typical and atypical examples as well as non-examples of geometric shapes when implementing the curriculum.

\subsection{Limitations and future research}

According to Burger \& Shaughnessy (1986), students may show different stages of reasoning in the tasks. Likewise, Mayberry (1983) claimed that a student can attain different thinking levels for different concepts or topics. Thus, the investigated topic of this study was the square. The results of the study should not be generalized to all geometry topics. In addition, the findings of this study should not be generalized to all preschool children in Turkey and in other countries. Cultural differences and educational facilities might be varied and affect the children's learning in mathematics. One may take this as advice to conduct similar research studies in other countries so as to gather more information about the perception of preschool children of different geometric shapes.

\section{Reference}

ARMSTRONG, J. M. Achievement and participation of women in mathematics: Results of two national surveys. Journal for Research in Mathematics Education, Reston, v. 12, n. 5, p. 356-372, 1981.

BOONEN, A. J. H.; KOLKMAN, M. E.; KROESBERGEN, E. H. The relation between teachers' math talk and the acquisition of number sense within kindergarten classrooms. Journal of School

Psychology, Orlando, v. 49, n. 3, p. 281-299, 2011.

BURGER, W. F.; SHAUGHNESSY, J. M. Characterizing the van Hiele levels of development in geometry. Journal for Research in Mathematics Education, Reston, v. 17, n. 1, p. 31-48, 1986.

CASEY, M. B.; ANDREWS, N.; SCHINDLER, H.; KERSH, J.; SAMPER, A.; COP-LEY, J. The development of spatial skills through interventions involving block building activities. Cognition and Instruction, Philadelphia, v. 26, n. 3, p. 269-309, 2008.

CLEMENTS, D. H. Geometric and spatial thinking in young children. In: COPLEY, J. V. (Ed.), Mathematics in the early years. Reston: National Council of Teachers of Mathematics, 1999, p. 6679.

CLEMENTS, D. H. Geometric and spatial thinking in early childhood education. In: CLEMENTS, D. H.; SARAMA, J.; DIBIASE. A. M. (Ed.). Engaging young children in mathematics: Standards for early childhood mathematics education. Mahwah: Erlbaum, 2004, p.7-72. 
CLEMENTS, D. H.; BATTISTA, M. T. Geometry and spatial reasoning. In: GROUWS, D. A. (Ed.), Handbook of research on mathematics teaching and learning. New York: Macmillan, 1992, p.420464.

CLEMENTS, D. H.; SWAMINATHAN, S.; HANNIBAL, M. A. Z.; SARAMA, J. Young children's concepts of shape. Journal for Research in Mathematics Education, Reston, v. 30, n. 2, p.192-212, 1999.

DUVAL, R. Geometrical pictures: Kinds of representation and specific processings. In: SUTHERLAND, R.; MASON, J. (Ed.). Exploiting Mental Imagery with Computers in Mathematics Education. Berlin: Springer-Verlag, 1995, p. 142-157.

DUVAL, R. Geometry from a cognitive point of view. In: MAMMANA, C.; VILLANI (Ed.). Perspectives on the Teaching of Geometry for the 21st century. Dordrecht: Kluwer Academic Publishers, 1998, p. 37-52.

DUVAL, R. A cognitive analysis of problems of comprehension in the learning of mathematics. Educational Studies in Mathematics, New York, v. 61, n.1\&2, p. 103-131, 2006.

ETHINGTON, C. A. Gender differences in a psychological model of mathematics achievement. Journal for Research in Mathematics Education, Reston, v. 23, n. 2, p. 166-181, 1992.

FORGASIZ, H. Gender and mathematics: re-igniting the debate. Mathematics Education Research Journal, Reston, v. 17, n. 1, p. 1-2, 2005.

FUJITA, T. Learners' level of understanding of inclusion relations of quadrilaterals and prototype phenomenon. The Journal of Mathematical Behavior, Orlando, v. 31, n. 1, p. 60-72, 2012.

FUJITA, T.; JONES, K. Primary trainee teachers' understanding of basic geometrical figures in Scotland. In: NOVOTANA, J.; MORAOVA. H.; MAGDELENA, K.; STEHLIKOVA, N. (Ed.). Proceedings of The 30th Conference of the International Group for the Psychology of Mathematics Education, Prague, v. 3, 2006, p.129-136.

FUYS, D.; GEDDES, D.; TISCHLER, R. The Van Hiele model of thinking in geometry among adolescents. Journal for Research in Mathematics Education Monograph. v. 3, p. i-196, 1988. GAGATSIS, A.; PATRONIS, T. Using geometrical models in a process of reflective thinking in learning and teaching mathematics. Educational Studies in Mathematics, v. 21, n. 1, p. 29-54, 1990.

GAL, H.; LINCHEVSKI, L. To see or not to see: Analyzing difficulties in geometry from the perspective of visual perception. Educational Studies in Mathematics, New York, v. 74, n. 2, p. 163-183, 2010.

GROSSMAN, H.; GROSSMAN, S. H. Gender Issues In Education. Needham Heights: Allyn \& Bacon, 1994.

HALAT, E. Sex-related differences in the acquisition of the van Hiele levels and motivation in learning geometry. Asia Pacific Education Review, Seoul, v. 7, n. 2, p. 173-183, 2006.

HALAT, E. Reform-based curriculum \& acquisition of the levels. Eurasia Journal of Mathematics, Science and Technology Education, Ankara, v. 3, n. 1, p. 41-49, 2007.

HALAT, E. In-service middle \& high school mathematics teachers: geometric reasoning stages and gender. The Mathematics Educator, Athens, v. 18, n. 1, p. 8-14, 2008. 
HALAT, E.; ŞAHIN, O. Van Hiele levels of pre- and in- service Turkish elementary school teachers and gender related differences in geometry. The Mathematics Educator, Singapore, v. 11, n. 1/2, p. 143-158, 2008.

HANNIBAL, M. A. Z.; CLEMENTS, D. H. Young children's understanding of basic geometric shapes. National Science Foundation Grant. ESI-8954644, 2000.

HERSHKOWITZ, R. The acquisition of concepts and misconceptions in basic geometry-Or when "a little learning is a dangerous thing.”. In: NOVAK, J. D. (Ed.). Proceedings of the second international seminar on Misconceptions and Educational Strategies in Science and Mathematics. Ithaca: Cornell University, v. 3, 1987, p. 236-251.

HERSHKOWITZ, R. Visualization in geometry: Two sides of the coin. Focus on Learning Problems in Mathematics, Framingham, v. 11, n. 1\&2, p. 61-76, 1989.

JONES, K. Theoretical frameworks for the learning of geometrical reasoning. Proceedings of the British Society for Research into Learning Mathematics, London, v. 18, n. 1\&2, p. 29-34, 1998.

KLIBANOFF, R. S.; LEVINE, S.; HUTTENLOCHER, J.; HEDGES, L. V.; VASILYEVA, M. Preschool children's mathematical knowledge: The effect of teacher 'math talk'. Developmental Psychology, Washington, v. 42, n. 1, p. 59-69, 2006.

LEVINE, S. C.; HUTTENLOCHER, J.; TAYLOR, A.; LANGROCK, A. Early sex differences in spatial skill. Developmental Psychology, Washington, v. 35, n.4, p. 940-949, 1999.

LLOYD, J. E. V; WALSH, J.; YAILAGH, M. S. Sex differences in performance attributions, selfefficacy, and achievement in mathematics: if I'm so smart, why don't I know it? Canadian Journal of Education, Ottawa, v. 28, n. 3, p. 384-408, 2005.

MASON, M. M. Paper presented at the Annual Meeting of the American Educational Research Association, San Francisco, USA, March. 1989.

MAYBERRY, J. The van Hiele levels of geometric thought in undergraduate preservice teachers. Journal for Research in Mathematics Education, Reston, v. 14, n. 1, p. 58-69, 1983. MCMILLAN, J. H. Educational research. Fundamentals for the consumers. 3. ed. New York: Addison Wesley, 2000.

NAEYC/NCTM. Early childhood mathematics: Promoting good beginnings. Washington: National Association for the Education of Young Children, 2002. Available at: $<$ http://www .naeyc.org/files/naeyc/file/positions/psmath.pdf> Accessed on: 5 Nov. 2014.

NATIONAL MINISTRY OF EDUCATION [MILLI EGITIM BAKANLIGI; MEB]. Turkish Preschool Education Program (Okul Öncesi Eğitim Programı). 2013. Ankara. Available at: <http://tegm.meb.gov.tr/dosya/okuloncesi/ooproram.pdf> Accessed on: 25 July. 2014.

NATIONAL COUNCIL OF TEACHERS OF MATHEMATICS (NCTM). Principles and Standards for School Mathematics, 2000. Math Standards and Expectations: Geometry Strand. Available at: $<\mathrm{h}$ ttp://www.nctm.org/standards/content.aspx?id=314> Accessed on: 9 Aug. 2014.

OBERDORF, C. D.; TAYLOR-COX, J. Shape up! Teaching Children Mathematics, Reston, v. 5, n. 6, p. 340-345, 1999.

RAZEL, M.; EYLON, B. S. Developing mathematics readiness in young children with the Agam Program. Paper presented at the fifteenth conference of the International Group for the Psychology of Mathematics Education, Genova, Italy, July. 1991. 
ROSCH, E. H. Natural categories. Cognitive Psychology, New York, v. 4, n. 3, p. 328-350, 1973.

RUDD, L. C.; LAMBERT, M. C.; SATTERWHITE, M.; ZAIER, A. Mathematical language in early childhood settings: What really counts? Early Childhood Educational Journal, New York, v. 36, n. 1, p. 75-80, 2008.

SIMON, M. A. Reconstructing mathematics pedagogy from a constructivist perspective. Journal for Research in Mathematics Education, Reston, v. 26, n. 2, p. 114-145, 1995.

SIMON, M. A.; TZUR, R.; HEINZ, K.; KINZEL, M. Explicating a mechanism for conceptual learning: Elaborating the construct of reflective abstraction. Journal for Research in Mathematics Education, Reston, v. 35, n. 5, p. 305-329, 2004.

VAN HIELE, P. M. Structure and insight: A theory of mathematics education. New York: Academic Press, 1986.

YESIL-DAGLI, U.; HALAT, E. Young Children's Conceptual Understanding of Triangle. Eurasia Journal of Mathematics, Science \& Technology Education, Ankara, v. 12, n.2, p. 189-202, 2016.

Submetido em Janeiro de 2015. Aprovado em Outubro de 2015. 